\title{
Treatment of ptosis in chronic progressive external ophthalmoplegia
}

\author{
CAROL M LANE AND J R O COLLIN \\ From Moorfields Eye Hospital, High Holborn and City Road, London
}

SUMMARY Seventeen patients with ptosis as a feature of chronic progressive external ophthalmoplegia were managed in accordance with a new protocol. An anterior approach levator advancement was performed on seven patients (13 lids) with more than $4 \mathrm{~mm}$ of levator function and a brow suspension procedure on eight patients (14 lids) with minimal levator function, in whom the frontalis muscle was relatively spared. Ptosis props were prescribed for two patients with a very weak orbicularis and poor lid closure. Six patients required long term lubricants, and one developed a postoperative corneal abscess associated with a poor Bell's phenomenon. Satisfactory elevation of the lids was achieved in 16 patients ( 25 lids).

The surgeon's choice of operation for ptosis correction is normally based on the degree of ptosis and the amount of levator function. ${ }^{1}$ However, in chronic progressive external ophthalmoplegia (CPEO) increasing weakness of the levator palpebrae superioris is accompanied by deterioration in function of the frontalis, orbicularis oculi, and external ocular muscles. There is a significant risk of postoperative corneal exposure due to lagophthalmos and a poor Bell's phenomenon. Surgery is indicated only if ptosis interferes with vision or causes considerable social embarrassment. In these circumstances a small degree of ptosis correction often provides a marked improvement in the patient's quality of life. This paper presents a protocol for the management of ptosis in patients with CPEO and the results of its use in 17 patients.

The treatment protocol was based on the relative power of the affected muscles. Patients with good levator function were treated with an anterior approach levator advancement. The anterior approach was used to help the identification of structures, since the levator muscle and aponeurosis often show fatty infiltration. It also avoids interference with the conjunctiva and the tear film, which is often compromised in patients with CPEO. ${ }^{2}$ Those with poor levator function but preserved frontalis action were treated by a brow suspension procedure. Lid props were prescribed when severe orbicularis weakness was demonstrable.

Correspondence to C M Lane, FRCS, Moorfields Eye Hospital, High Holborn, London WC1V 7 AN.
CPEO may be considered as a gradually progressive external ophthalmoplegia which occurs in several disease states with numerous associated findings, hence Drachman's term, 'ophthalmoplegia plus'. ${ }^{3}$ Some of the more common associations and other disorders which occasionally cause CPEO are listed in Table 1 . Patients with myotonic dystrophy may give a history of autosomal dominant inheritance and have a classical long thin facies, frontal balding, and cataract. ${ }^{4}$ Ptosis is marked, and there may be slowing or limitation of external ocular movements. ${ }^{5}$ Kearns and Sayre ${ }^{6}$ described a syndrome in which CPEO and heart block occurred before the age of 20 years, with diverse associated features and the later development of pigmentary retinopathy. Similar hereditary diseases include

Table 1 Conditions associated with or causing CPEO

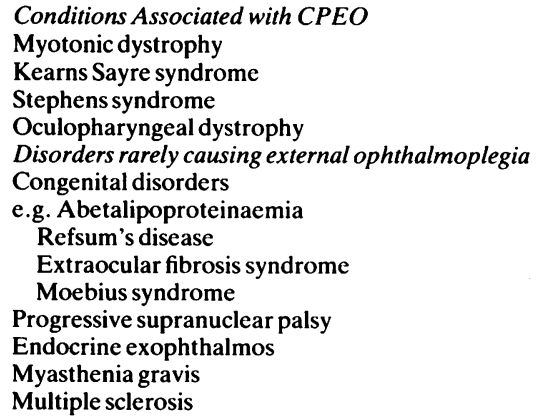


Stephens syndrome ${ }^{7}$ of CPEO, cerebellar ataxia and peripheral neuropathy, and oculopharyngeal dystrophy in which ptosis, mild restriction of eye movements, and dysphagia with autosomal dominant inheritance occur after 40 years of age. ${ }^{8}$ Abetalipoproteinaemia ${ }^{9}$ and Refsum's disease ${ }^{10}$ are among rare congenital disorders which sometimes feature external ophthalmoplegia. Patients with ocular fibrosis syndrome have static restriction of ocular movement, with reduced movement of the globe on forced duction.

These syndromes must be differentiated from acquired brainstem disease, such as progressive supranuclear palsy, and from multiple sclerosis. Dysthyroid eye disease may rarely present in clinically euthyroid" ptotic patients, but the symptom of diplopia, uncommon in other forms of CPEO, together with particular restriction of elevation and abduction of the globe, may assist diagnosis. Myasthenia gravis is recognisable by the presence of muscle fatigue with a reduced number of acetylcholine receptors and a positive response to edrophonium, an anticholinesterase. ${ }^{12}$ Weakness of the external ocular muscles is often asymmetrical and momentary retraction of the upper eyelid may be observed during refixations from down to straight ahead. ${ }^{13}$ Surgical correction of myasthenic ptosis is influenced by the medical status of the patient and has an unpredictable outcome; patients with myasthenia gravis were therefore excluded from the study.

\section{Subjects and methods}

Seventeen patients with severe ptosis and CPEO presented to the Lid Clinic at Moorfields Eye Hospital over a period of six years (Table 2). Patients with mild ptosis were not included in the study. Eleven patients had features of systemic disease: four had the Kearns-Sayre syndrome, two had oculopharyngeal dystrophy, four had myotonic dystrophy, and one had progressive multiple sclerosis. In all cases the diagnosis was confirmed by a neurologist. Specimens from triceps muscle biopsy in five patients, four of whom had Kearns-Sayre syndrome, had shown ragged red fibres, a marker for mitochondrial abnormalities. ${ }^{14}$ At presentation a full clinical history was taken from each patient. Specific questions referred to the duration and variability of the ptosis, the use of props, diplopia, and the degree of disability suffered.

The palpebral aperture was measured with the patient looking straight ahead and levator function was measured from full downgaze to full upgaze with the frontalis muscle held fixed against the brow. The distance from the lid margin to the upper lid skin crease was noted when the latter was present. Bell's
Table 2 Patients treated for ptosis in CPEO

\begin{tabular}{|c|c|c|c|c|c|c|}
\hline $\begin{array}{l}\text { Patient } \\
\text { no. }\end{array}$ & $\begin{array}{l}\text { Ageat } \\
\text { onset of } \\
\text { ptosis (yr) }\end{array}$ & Sex & Diagnosis & $\begin{array}{l}\text { Surgery and } \\
\text { age (yr) }\end{array}$ & Results & $\begin{array}{l}\text { Follow- } \\
\text { up }(y r)\end{array}$ \\
\hline 1 & 10 & $\mathbf{F}$ & Mit.M & $\begin{array}{l}\text { R\&L ALA } \\
\quad 24\end{array}$ & $\begin{array}{l}\text { Abscess } \\
\text { Lubric. }\end{array}$ & 3 \\
\hline 2 & 19 & $\mathbf{F}$ & MD & $\begin{array}{l}\text { R\&L ALA } \\
55\end{array}$ & Good & 2 \\
\hline 3 & 33 & $\mathbf{M}$ & OD & $\begin{array}{l}\text { R\&L ALA } \\
\quad 46\end{array}$ & Good & 3 \\
\hline 4 & 51 & $\mathbf{M}$ & OD & $\begin{array}{l}\text { R\&L ALA } \\
59\end{array}$ & Good & 3 \\
\hline 5 & 41 & $\mathrm{~F}$ & CPEO & $\begin{array}{c}\text { R ALA } \\
61\end{array}$ & Lubric. & $1 \cdot 5$ \\
\hline 6 & 43 & $\mathrm{~F}$ & MD & $\begin{array}{l}\text { R\&L ALA } \\
\quad 51\end{array}$ & Good & 2 \\
\hline 7 & 58 : & $\mathrm{F}$ & CPEO & $\begin{array}{l}\text { R\&L ALA } \\
73\end{array}$ & Good & 3 \\
\hline 8 & 7 & $\mathrm{~F}$ & CPEO & $\begin{array}{l}\text { R\&LSBS } \\
\quad 62\end{array}$ & Lubric. & $\begin{array}{l}0.5 \\
1.5\end{array}$ \\
\hline 9 & 11 & $\mathbf{M}$ & KS & $\begin{array}{c}\mathrm{R} \& \mathrm{~L} \text { ABS } \\
\quad 41\end{array}$ & Lubric. & 1 \\
\hline 10 & 11 & $\mathbf{F}$ & KS & $\begin{array}{l}\text { R\&L ABS } \\
15\end{array}$ & Lubric. & 7 \\
\hline 11 & 12 & $\mathbf{M}$ & KS & $\begin{array}{l}\text { R\&L ABS } \\
20\end{array}$ & $\begin{array}{r}\text { Bands cut } \\
\text { Ptotic }+\end{array}$ & 5 \\
\hline 12 & 16 & $\mathbf{M}$ & KS & $\begin{array}{c}\text { LSBS } \\
49\end{array}$ & Lubric. & 1 \\
\hline 13 & 24 & $\mathbf{M}$ & CPEO & $\begin{array}{l}\mathrm{R} \& \mathrm{~L} \text { ABS } \\
59\end{array}$ & Good & 1 \\
\hline 14 & 39 & $\mathrm{~F}$ & MD & $\begin{array}{c}\text { R SBS } \\
39\end{array}$ & Good & $2 \cdot 5$ \\
\hline 15 & 64 & $\mathbf{F}$ & MS & $\begin{array}{l}\text { R\&LSBS } \\
78\end{array}$ & Good & $1 \cdot 5$ \\
\hline $\begin{array}{l}16 \\
17\end{array}$ & $\begin{array}{l}16 \\
51\end{array}$ & $\begin{array}{l}\mathbf{M} \\
\mathbf{M}\end{array}$ & $\begin{array}{l}\text { MD } \\
\text { CPEO }\end{array}$ & $\begin{array}{l}\text { spectacle-bo } \\
\text { scleral lens }\end{array}$ & rne $\}$ Ptos & props \\
\hline
\end{tabular}

Mit.M=Mitochondrial myopathy featuring CPEO. $\mathrm{KS}=$ KearnsSayre syndrome. $\mathrm{MD}=$ Myotonic dystrophy. $\mathrm{MS}=$ Multiple sclerosis. $\mathrm{OD}=$ Oculopharyngeal dystrophy. $\mathrm{CPEO}=$ Chronic progressive external ophthalmoplegia. ALA = Anterior levator advancement. $\mathrm{SBS}=\mathrm{B}$ row suspension using stored fascia . $\mathrm{ABS}=$ Brow suspension using autologous fascia. . Lubric. $=$ Lubricants required; good lid position.

phenomenon and orbicularis and frontalis muscle function were assessed, and any evidence of corneal exposure was noted.

Surgery was performed to elevate the lids only if the ptosis occluded the visual axis or severely affected social function and some orbicularis function was present. If levator palpebrae superioris function was more than $4 \mathrm{~mm}$, an anterior levator advancement, with aponeurotic resection or reinsertion, was performed under local anaesthetic, ${ }^{15}$ the skin crease being set arbitrarily at $7 \mathrm{~mm}$ from the lid margin or being measured to match the other side. Patients with less than $4 \mathrm{~mm}$ of levator function and preserved frontalis action were treated by a brow suspension procedure. ${ }^{16}$ If the patient was young, with good cardiac function, bilateral brow suspension procedures were performed under general anaesthetic 
by the Crawford technique ${ }^{1718}$ and autologous fascia lata. The anaesthetist was consulted at an early stage, and halothane, barbiturates, and suxamethonium were avoided.$^{19}$ In older patients, and where general anaesthesia was contraindicated, homologous fascia lata, stored in $70 \%$ alcohol and then soaked in saline for 12 hours and rinsed in soframycin $2 \%$ for 1 hour preoperatively, was inserted under local anaesthesia by the technique described by Fox. ${ }^{20}$ Strips of stored fascia were cut $3 \mathrm{~mm}$ wide to ensure adequate strength, and the patients receiving them were given a five-day course of systemic antibiotic.

With both an anterior approach advancement and a brow suspension procedure the eyelid level was adjusted at surgery under local anaesthesia so that it was just clear of the pupillary axis with the patient voluntarily opening the eye. With a brow suspension under general anaesthesia the upper eyelid was positioned so that the lid was closed but just beginning to open at the end of the procedure. A 4/0 silk suture, inserted into the lower eyelid over a bolster and drawn up to the brow ${ }^{21}$ protected the cornea under the dressing. When the dressing was taken off 48 hours after surgery, the suture was taped to the cheek for 24 hours and removed at the end of this period if there was no evidence of corneal exposure; traction to the lower lid could be reapplied if this occurred. All patients were prescribed local antibiotic and lubricant drops on a 1/2 to 2 hourly basis.

All patients were reviewed at three or four monthly intervals in the clinic, with particular attention being paid to corneal exposure, and they were instructed to report immediately should the eye become painful, red, or start discharging pus.

\section{Results}

The series included four patients, three male and one female, with the Kearns-Sayre syndrome and an average age of onset of 12.5 years, and a fifth with mitochondrial myopathy without the complete syndrome; five with CPEO in isolation at the time of treatment, four of whom developed ptosis after the age of 20; two with oculopharyngeal dystrophy; four with myotonic dystrophy and an average age of 33.5 years at the onset of ptosis; and one with progressive multiple sclerosis. An anterior levator advancement was performed on seven patients (13 lids) with a mean levator function of $6.6 \mathrm{~mm}$ and a mean palpebral aperture of $4.4 \mathrm{~mm}$. In no patient was preoperative levator function more than $8 \mathrm{~mm}$. Two patients (four lids) responded to reinsertion of the aponeurosis and the remainder (nine lids) required an average resection of $9 \mathrm{~mm}$. An example of the appearance of case 3 preoperatively and six months postoperatively is shown in Figs. 1a, b. In several

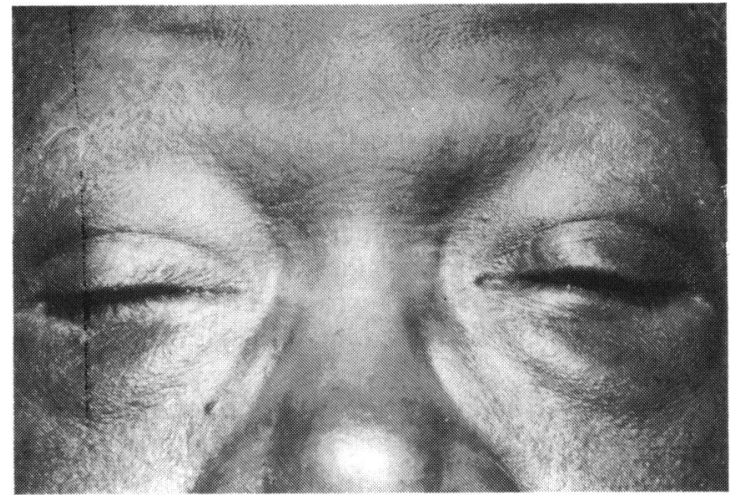

Fig. 1a

Fig. 1 A 46-year-old man with oculopharyngeal dystrophy, a 13-year history of ptosis, and dysarthria for three years.

(a) Preoperative. (b) Six months after bilateral anterior levator resection.

cases histopathological study confirmed the fatty nature of the aponeurosis and levator muscle, and in one case mitochondrial inclusions were seen. Postoperatively there was little change in the mean levator function $(7 \mathrm{~mm})$, but the mean palpebral aperture increased to $7.6 \mathrm{~mm}$. The mean follow-up was 30 months, ranging from 18 to 36 months.

Bilateral brow suspension with autologous fascia lata was performed on four patients with a mean age of 34 years, and stored fascia was used for another four patients (six lids) with a mean age of 62 years. The mean preoperative palpebral aperture was the same as for those patients with fair levator function, $4.4 \mathrm{~mm}$, but mean levator function was only $3.6 \mathrm{~mm}$. Postoperatively the mean palpebral aperture was 6.5 $\mathrm{mm}$. The average follow-up was 30 months, ranging from 6 to 84 months.

Two patients with poor orbicularis muscle function were satisfactorily fitted with ptosis props.

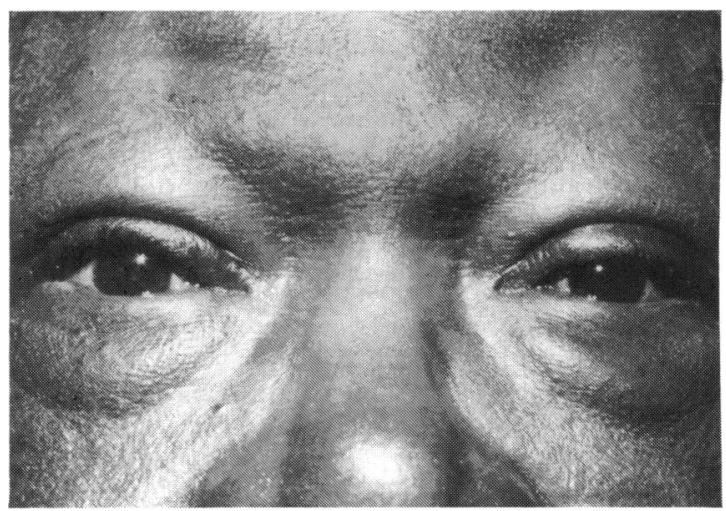

Fig. 1b 


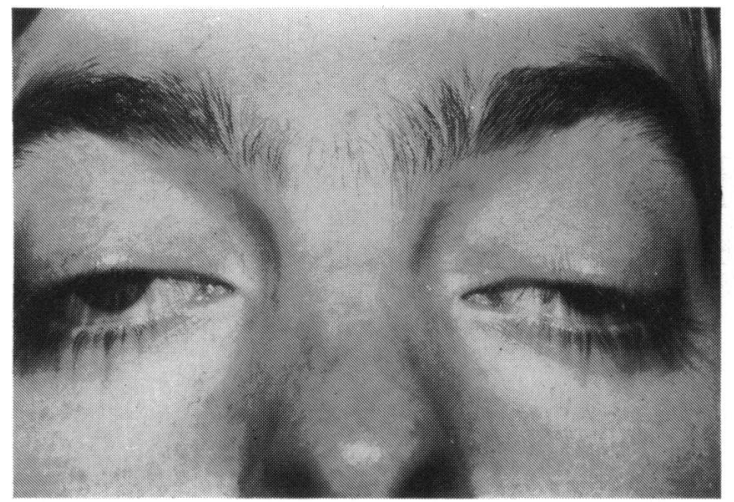

Fig. 2a

Fig. 2 A boy of 15 years with the Kearns-Sayre syndrome and a two-year history of increasing ptosis. (a) Preoperative. (b) One year after bilateral brow suspension with autologous fascia lata. (c) Following resection of fascial bands.

A 25-year-old woman developed a corneal abscess two months after a $10 \mathrm{~mm}$ right anterior levator resection. The palpebral aperture was only $7 \mathrm{~mm}$ but there was some lagophthalmos. The localised abscess resolved completely with appropriate medical therapy and there have been no further complications. Case 11, who had rapidly advancing ophthalmoplegic disease, developed marked corneal exposure within 12 months of a brow suspension procedure (Figs. 2a, b, c). The fascial bands on both lids were divided, and he has since developed recurrent occlusion of the visual axes. His facial muscles are now so weak that lid props are appropriate.

\section{Discussion}

Ptosis becomes a physical disability when the upper eyelid occludes the visual axis. The patient attempts to compensate by brow elevation and the adoption of

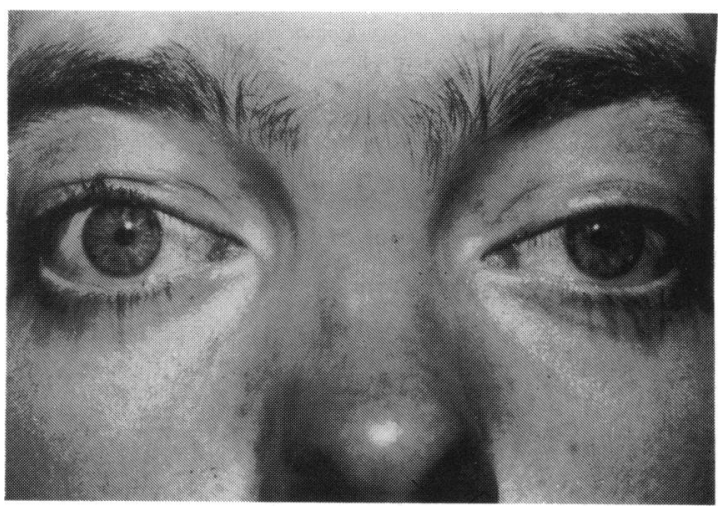

Fig. 2b

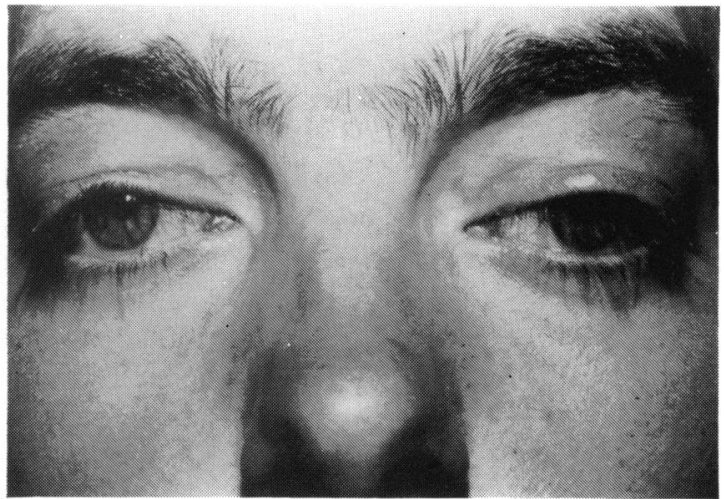

Fig. 2c

an abnormal head posture with elevation of the chin. Surgery is often avoided for fear of corneal exposure problems. Ptosis props are usually not well tolerated by patients with early CPEO, but they are particularly useful when lid closure is very poor or the degree of ptosis is variable, as in myasthenia gravis. The long term use of scleral prop contact lenses may be associated with corneal pannus formation, though this has not occurred in the two cases described in this series. If the levator function is poor but frontalis action is good, we recommend a brow suspension. The patient must be warned that in either case the ptosis may recur if the levator or frontalis muscle becomes weaker. Alternatively corneal exposure may occur if the orbicularis muscle weakens and lid closure becomes defective. A lid lowering procedure may then be required, and eventually the patient may need ptosis props.

Corneal exposure did occur in this series after both levator resection and brow suspension, but bilateral upper lid lowering was required in only one case. Six patients, however, need lubrication in the form of hydroxymethylcellulose or $0.5 \%$ polyvinylpyrrolidine alkaline eye drops and with simple eye ointment at night, and two also tape their lids closed at night. These patients have shown marked reluctance to have upper lid lowering and would far rather persist with the insertion of drops and ointment than risk returning to their former ptotic state. The functional and cosmetic improvement following a brow suspension procedure in case 15 is shown in Figs. 3a, b. Some surgeons prefer the use of silicone to fascia for brow suspension, and its easy removal may facilitate lid lowering if required. As a foreign material it can easily become infected, and, although stored fascia can present similar problems, they are extremely rare in our experience and did not occur in this series. One patient, not included in this series, was treated with a blepharoplasty with a good result but marked lagophthalmos, requiring the frequent use of lubri- 


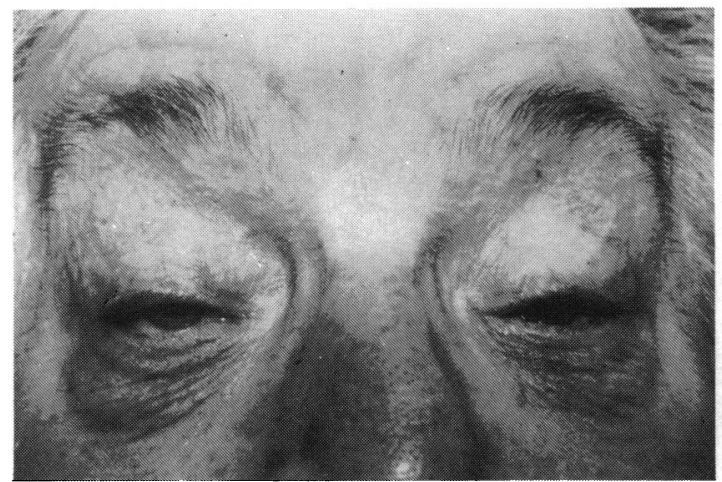

Fig. 3a

Fig. 3 A 78-year-old woman with multiple sclerosis who underwent bilateral brow suspension with stored homologous fascia. (a) Preoperative. (b) Six months after surgery.

cants. This procedure is not so easily reversed as those described here. Three patients with CPEO, treated for ptosis in other centres with a conventional degree of levator resection, have required surgical recession of the upper eyelid retractors because of corneal exposure.

In conclusion, we believe that if the orbicularis muscle function is very poor ptosis props are indicated, but if eyelid closure is fair patients are very much happier with surgical ptosis correction. Either a levator advancement or a brow suspension procedure should be performed, depending on the relative function of the levator and frontalis muscles. Corneal exposure problems may occur subsequently as the condition progresses and tear production decreases. It may be possible to improve corneal protection by raising and tightening the lower eyelid, but the surgeon must be prepared to lower the upper eyelid if the cornea cannot be preserved by this means or by using conservative measures. Patients must understand this before undergoing a ptosis correction. In this series all the patients who had ptosis surgery were most appreciative. They accept that more surgery may be necessary. The follow-up period is short, but we believe that this series justifies cautious surgery in the management of ptosis associated with CPEO.

\section{References}

1 Beard C. The surgical treatment of blepharoptosis: a quantitative approach. Trans Am Ophthalmol Soc 1966; 64: 401-87.

2 Anderson RL, Dixon RS. Neuromyopathic ptosis. A new surgical approach. Arch Ophthalmol 1979; 79: 1129-31.

3 Drachman DA. Ophthalmoplegia plus. The neuro-degenerative disorders associated with progressive external ophthalmoplegia. Arch Neurol 1968; 18: 654-74.

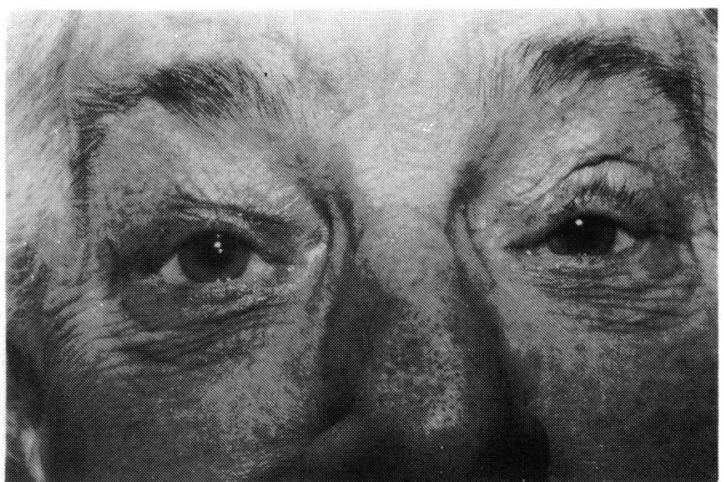

Fig. 3b

4 Burian HM, Burns CA. Ocular changes in myotonic dystrophy. Am J Ophthalmol 1967; 63: 22-34.

5 Lessel S, Copetto J, Sahet S. Ophthalmoplegia in myotonic dystrophy. Am J Ophthalmol 1971; 97: 1231-5.

6 Kearns TP, Sayre GP. Retinitis pigmentosa, external ophthalmoplegia and complete heart block. Arch Ophthalmol 1958; 60: 280-9.

7 Stephens J, Hoover ML, Denst J. On familial ataxia, neural amyotrophy and their association with progressive external ophthalmoplegia. Brain 1958; 81: 556-66.

8 Victor M, Hayes R, Adams RD. Oculopharyngeal muscular dystrophy. N Engl J Med 1962; 267: 1267-72.

9 Yee RD, Cogan DG, Zee DS. Ophthalmoplegia and dissociated nystagmus in abetalipoproteinemia. Arch Ophthalmol 1976; 94: 571-5.

10 Refsum S. Heredopathia atactia polyneuritiformis, phytanic acid storage disease (Refsum's disease) with particular reference to ophthalmological disturbances. Metab Pediatr Syst Ophthalmol 1977; 1: 73-9.

11 Hall R, Anderson J, Smart GA, Besser GM. Fundamentals of clinical endocrinology. Philadelphia: Lippincott, 1974: 68-137.

12 Daroff RB. Ocular myasthenia: diagnosis and therapy. In: Glaser JS, ed. Neuro-ophthalmology Symposium of the University of Miami and Bascom Palmer Eye Institute. St Louis, Mosby, 1980; 10: 62-71

13 Cogan DG. Myasthenia gravis: a review of the disease and a description of the lid twitch as a characteristic sign. Arch Ophthalmol 1965; 74: 217-21.

14 Morgan-Hughes JA, Mair WGP. Atypical muscle mitochondria in oculoskeletal myopathy. Brain 1973; 96: 215-24.

15 Collin JRO. A manual of systematic lid surgery. Edinburgh: Churchill Livingstone, 1983: 44-64.

16 Kemp E, James CR, Collin JRO. The treatment of ptosis by brow suspension. Trans Ophthalmol Soc UK 1986; 105: 84-7.

17 Crawford JS. Repair of ptosis using frontalis muscle and fascia lata. Ophthalmology (Rochester) 1956; 60: 672-8.

18 Crawford JS. Repair of ptosis using frontalis muscle and fascia lata: a 20 year review. Ophthalmic Surg 1977; 8: 31-6.

19 Carroll JE, Zwillich C. Weil JV. Depressed ventilatory response in oculocraniosomatic neuro-muscular disease. Neurology 1976; 26: $140-6$.

20 Fox SA. Congenital ptosis II; frontalis sling. J Pediatr Ophthalmol 1966; 3: 25-8.

21 Frost AD. Supporting suture in ptosis operations. Am J Ophthalmol 1934; 17: 633.

Accepted for publication 26 June 1986. 